\title{
СТАНДАРТИЗАЦИЯ КАК СПОСОБ СНИЖЕНИЯ РИСКОВ КОММЕРЧЕСКОГО ИПОТЕЧНОГО КРЕДИТОВАНИЯ
}

\section{STANDARDIZATION AS A WAY TO REDUCE THE RISKS OF COMMERCIAL MORTGAGE LENDING}

\section{A. Ushanov}

Summary. A loan secured by commercial real estate (commercial mortgage), being one of the most popular types of corporate loans, has a number of undeniable advantages over other types of borrowing. At the same time, this product is characterized by specific risks, which are often the reason for refusal of lending or their implementation in the course of debt servicing: unacceptable for the lender level of capitalization and liquidity of collateral, the degree of occupancy of commercial real estate and indexation of rates under lease agreements; whether the object is not suitable for commercial use; whether the accepted collateral is encumbered with other obligations, etc. One of the ways to improve the process of commercial mortgage lending in order to reduce transaction risks is to standardize it. In the article, as part of the proposal to develop a Standard for the process of lending secured by commercial real estate, a Matrix of requirements for the components of this process is provided, reflecting the best practices of leading domestic banks working in the field of commercial mortgages.

Keywords: commercial mortgage, credit risk, process approach, business process of the Bank, the standards of banking activities.

\author{
Уианов Александр Евгеньевич \\ К.э.н., дочент, Финансовый университет при \\ Правительстве РФ (г. Москва) \\ Ushanov_0656@mail.ru
}

Аннотация. Кредит под залог коммерческой недвижимости (коммерческая ипотека), являясь одним из самых востребованных видов корпоративных кредитов, обладает рядом неоспоримых преимуществ по сравнению с другими видами заимствования. В то же время данному продукту свойственны специфические риски, часто являющимися причиной отказа от кредитования или их реализации в ходе обслуживания долга: неприемлемые для кредитора уровень капитализации и ликвидности залога, степень заполняемости объекта коммерческой недвижимости и индексации ставок по договорам аренды; арендонепригодность объекта для коммерческого использования; наличие обременения принимаемого залога иными обязательствами и др. Одно из направлений совершенствования процесса коммерческого ипотечного кредитования в целях снижения рисков сделок его стандартизация. В статье в рамках предложения о разработке Стандарта процесса кредитования под залог коммерческой недвижимости приводится Матрица требований по составляющим указанного процесса, отражающая лучшие практики ведущих отечественных банков, работающих в сфере коммерческой ипотеки.

Ключевые слова: коммерческая ипотека, кредитные риски, процессный подход, бизнес-процесс банка, стандарты банковской деятельности.

Преимуществами коммерческой ипотеки являются развитие и расширение бизнеса заемщика, генерирование прибыли как результат использования коммерческих объектов, оптимизация налогообложения (уплата процентов по кредиту относится на расходы компании).

Данный вид займов выгоден как заемщику, так и банку. Первые имеют возможность срочно получить необходимую сумму денег на любые нужды - расширение бизнеса, пополнение оборотных средств, возможность финансировать крупные сделки [1] [2] [3], вторые получают ликвидное имущество, быстрая продажа которого покроет убытки в случае невыполнения заемщиком условий погашения ссуды. Главным преимуществом данной разновидности банковских продуктов является то, что коммерческая недвижимость остается в распоряжении клиента, что дает возможность получать доход от ее использования. 
Кроме этого, достаточно привлекательны сами параметры заимствования: относительно низкая, по сравнению с большинством других кредитных программ, процентная ставка, длительный срок возврата, посильный размер ежемесячных платежей, а также лояльность к заемщику и индивидуальные условия сделки.

\section{Условия, ограничения и риски}

Существуют строгие ограничения на собственность, которую можно использовать в качестве обеспечения кредита. Ликвидной коммерческой недвижимостью считаются объекты, применяемые для получения прибыли или роста капитала. Такая собственность не пригодна для проживания и приносит предпринимателю стабильный доход. Залоговым имуществом может выступать офисная недвижимость: кабинеты, здания, офисы, бизнес-центры и т.д.; индустриальная собственность: производственные цеха, склады, объекты для хранения товаров и т.д.; розничная недвижимость: магазины, фитнес-центры, гостиницы, торговые центры и т.д.

Типовыми условиями предоставления кредита в форме коммерческой ипотеки являются следующие:

- валюта кредитования - рубли;

- размер ссуды составляет 70-80\% от рыночной стоимости объекта залога;

- график погашения кредита - ежемесячный /ежеквартальный; составляется, как правило, так, чтобы отношение чистого операционного дохода к сумме погашаемого «тела» кредита и процентов было не менее 1,2 в каждом отчетном периоде. Допускается погашение части ссуды в конце срока кредитования (баллон), но в объеме не более $50 \%$ от рыночной стоимости объекта;

- страхование объекта недвижимости на рыночную стоимость;

- перевод 95-100\% доходов от аренды объектов недвижимости на расчетный счет в банке-кредиторе.

При принятии решения о возможности совершения сделки кредитная организация осуществляет комплексный анализ основных аспектов финансово-хозяйственной деятельности заемщика, включающий:

- тщательное изучение балансов компании за последние 4-6 отчетные даты;

- оценку длительности ее пребывания на данном рынке, степень успешности бизнеса и т.п.);

- оценку уровня ликвидности, определение рыночной стоимости залога.

Для проведения указанного анализа заемщик представляет в банк пакет документов, перечень которых представлен на стр. 14 (см. Матрицу требований...).
Коммерческая ипотека, не имея должного законодательного регулирования, несет определенные специфические риски для кредитных организаций, которые зачастую являются причиной отказа от кредитования, либо, что намного хуже, реализуются в ходе обслуживания долга. Этим объясняется, в частности, готовность банков предоставлять бизнесу ссуды под залог коммерческой недвижимости в размере $70-80 \%$ от ее рыночной стоимости. К таким рискам относятся:

- риски капитализации (стоимость в случае продажи) и ликвидности (возможность оперативно и выгодно реализовать залог). Как только появляется просроченная задолженность по ссуде и заложенная недвижимость переходит в собственность банка, все риски либо, наоборот, выгодные перспективы также ложатся на банк;

- оформление правоустанавливающих документов в ненадлежащем порядке;

- отсутствие разрешения на использование земли под объектом;

- арендонепригодность объекта для коммерческого использования;

- наличие обременения принимаемого залога иными обязательствами;

- заполняемость объекта коммерческой недвижимости (бизнес-центр и др.) ниже прогнозируемой при проработке проекта;

- индексация ставок по договорам аренды ниже прогнозируемой при проработке проекта;

- наличие низколиквидных или специальных объектов (пожарного водоема, газохранилища, котельной, трансформаторной подстанции), которые являются неотъемлемой частью имущественного комплекса и др.

Одним из путей совершенствования бизнес-процесса кредитования компаний под залог коммерческой недвижимости, в целях снижения рисков сделок является его стандартизащия.

\section{СтанАартизашия прочесса креАитования поА залог коммерческой неАвижимости}

Стандарты - это имеющие сугубо практическое назначение требования к организации процессов производства банковских продуктов, отраженные в соответствующем документе и применяемые кредитными организациями добровольно на постоянной основе. В основе документа о стандарте - передовой зарубежный и отечественный опыт управления, лучшая банковская практика, международные стандарты.

В России разработка стандартов банковской деятельности - прерогатива Ассоциации российских бан- 
Таблица 1. Матрица требований по составляющим процесса кредитования инвестиционных проектов (продолжение на стр. 74)

\begin{tabular}{|c|c|c|}
\hline $\begin{array}{l}\text { NN } \\
n / \Pi\end{array}$ & $\begin{array}{l}\text { Составляющие требова- } \\
\text { ний Стандарта }\end{array}$ & Содержание требований Стандарта \\
\hline 1 & Цель кредитования & $\begin{array}{l}\text { Крупный и средний бизнес: } \\
\text { • } \\
\text { • } \\
\text { часширение всего - приобретение нового оборудования, земли, центра розничной торговли } \\
\text { и т.п. } \\
\text { • } \quad \text { наиболее распространенный вид — нецелевой кредит на крупную сумму. } \\
\text { Малый бизнес: } \\
\text { п пкопка объектов жилой недвижимости для предпринимательской деятельности, } \\
\text { ремонт коммерческого имущества, строительство объекта для предпринимательской } \\
\text { деятельности. }\end{array}$ \\
\hline 2 & Срок кредитования & От 3 лет до 10 лет \\
\hline 3 & Обеспечение по кредиту & 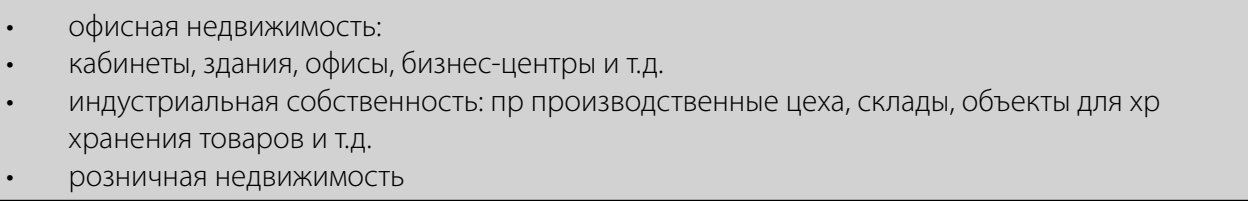 \\
\hline 4 & $\begin{array}{l}\text { Процентная ставка } \\
\text { по кредиту }\end{array}$ & 9,5-17\% годовых \\
\hline 5 & $\begin{array}{l}\text { Условия погашения } \\
\text { кредита }\end{array}$ & 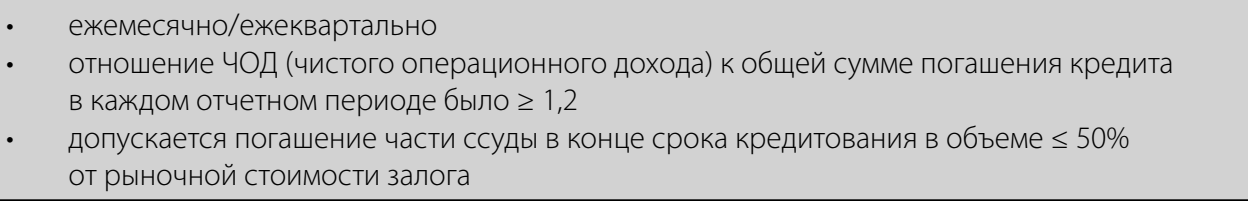 \\
\hline 6 & $\begin{array}{l}\text { Способы погашения } \\
\text { кредита }\end{array}$ & $\begin{array}{ll}\text { • } & \text { перевод средств со счета, принадлежащего ИП, физ. лицу или компании } \\
\text { • } & \text { внесение наличных денег в кассу банка } \\
\text { • } & \text { использование терминалов }\end{array}$ \\
\hline 7 & $\begin{array}{l}\text { Требования к информации } \\
\text { заемщике }\end{array}$ & $\begin{array}{l}\text { • } \\
\text { история образования, учредители, количество сотрудников, преобладающие виды } \\
\text { деятельности, профильная продукция, опыт работы в отрасли, сведения контрагентах } \\
\text { и конкурентах, кредитная история } \\
\text { собственником какой недвижимости является: общая площадь объекта, арендопригодная } \\
\text { площадь, адрес объекта } \\
\text { сведения о собственнике заемщика: юридический статус, опыт работы в недвижимости, } \\
\text { информация о других активах и обязательствах } \\
\text { основные конкуренты, расположенные в районе (бизнес-центры, ТРЦ и т.п.) }\end{array}$ \\
\hline 8 & $\begin{array}{l}\text { Требования к объекту } \\
\text { коммерческой } \\
\text { недвижимости }\end{array}$ & 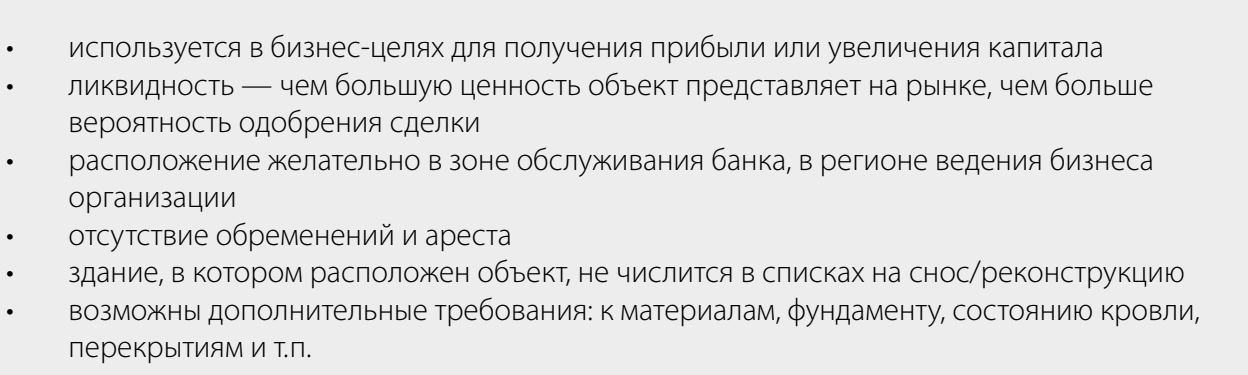 \\
\hline 9 & $\begin{array}{l}\text { Проведение } \\
\text { маркетинговых } \\
\text { исследований }\end{array}$ &  \\
\hline
\end{tabular}




\section{Таблица 1 (продолжение). Матрица требований по составляющим процесса кредитования инвестиционных проектов (продолжение на стр. 75)}

\begin{tabular}{|c|c|c|}
\hline $\begin{array}{l}\text { NN } \\
\pi / \Pi\end{array}$ & $\begin{array}{l}\text { Составляющие требова- } \\
\text { ний Стандарта }\end{array}$ & Содержание требований Стандарта \\
\hline 10 & $\begin{array}{l}\text { Требования при расчете } \\
\text { финансовой модели }\end{array}$ & 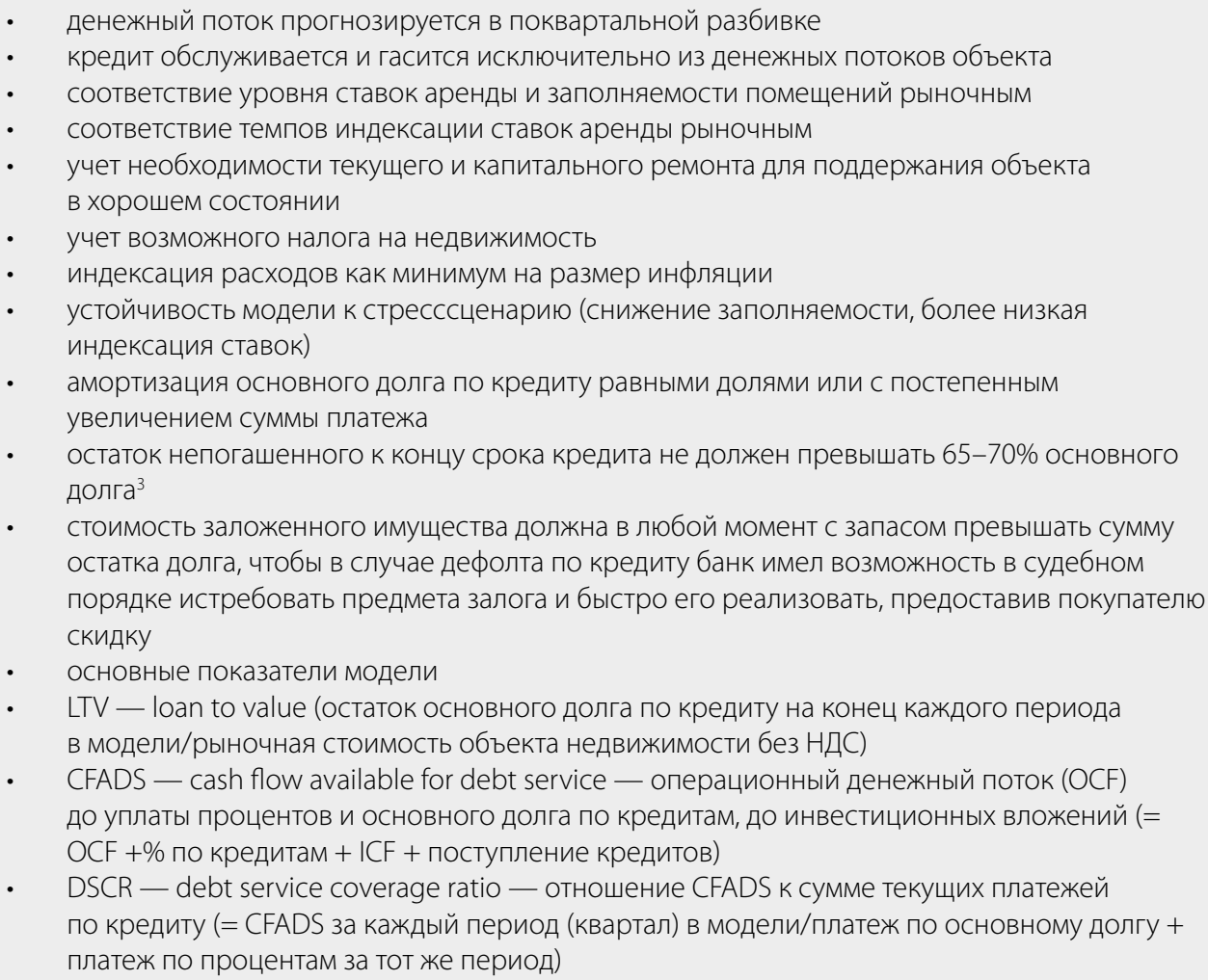 \\
\hline 11 & $\begin{array}{l}\text { Требования к составу } \\
\text { договорной и иной } \\
\text { документации }\end{array}$ & 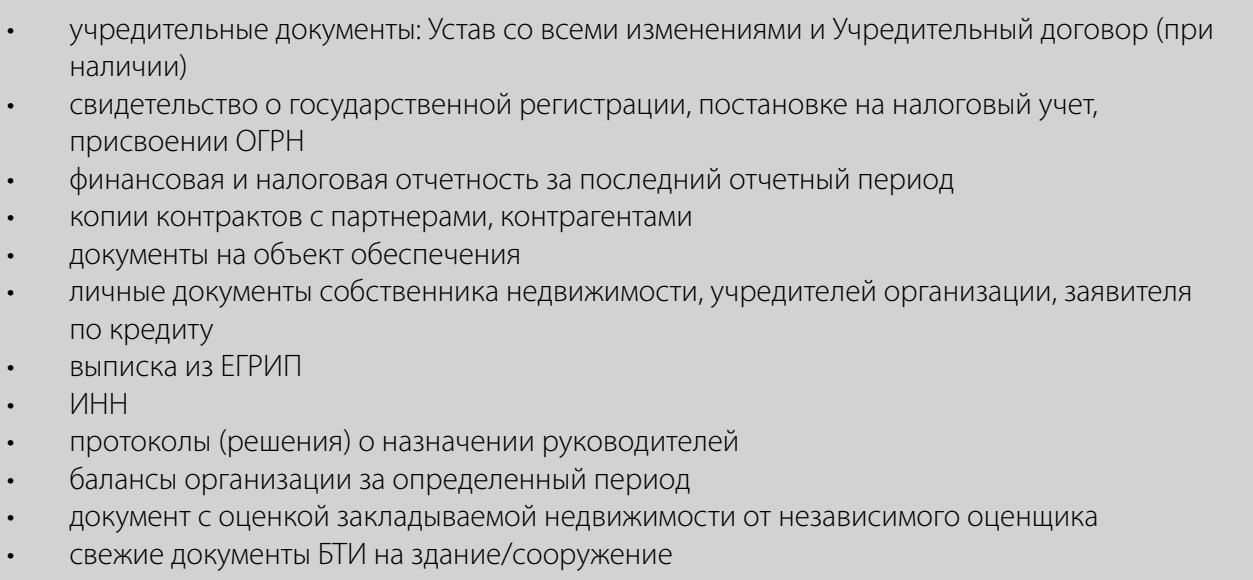 \\
\hline 12 & $\begin{array}{l}\text { Организация оценки } \\
\text { эффективности проекта }\end{array}$ & $\begin{array}{l}\text { Анализ кредитующим подразделением: } \\
\text { • } \quad \text { инвестиционных возможностей компании, эффективности проекта, реальности } \\
\text { источников погашения, рисков проекта } \\
\text { • } \quad \text { показателей бизнес-плана }\end{array}$ \\
\hline
\end{tabular}

\footnotetext{
1 Изучить сайты агентств - Knight Frank, SA Ricci, JLL, сайты по аренде - cian.ru, прочие источники - Ведомости, РБК и др.

2 Стоимость объекта = NOI (чистый операционный доход) / сар. rate (ставка капитализации)

${ }^{3}$ Эта цифра может быть больше или меньше, важно, чтобы к концу срока кредитования заемщик мог свободно рефинансировать остаток долга в другом банке или погасить кредит из накопленных свободных средств
} 
Таблица 1 (продолжение). Матрица требований по составляющим процесса кредитования инвестиционных проектов

\begin{tabular}{|c|c|c|}
\hline $\begin{array}{l}\text { NN } \\
\Pi / \Pi\end{array}$ & $\begin{array}{l}\text { Составляющие требова- } \\
\text { ний Стандарта }\end{array}$ & Содержание требований Стандарта \\
\hline 13 & $\begin{array}{l}\text { Распределение функцио- } \\
\text { нальных обязанностей }\end{array}$ & $\begin{array}{l}\text { - } \quad \text { наличие выделенных кредитных специалистов либо самостоятельного инвестиционного } \\
\text { подразделения } \\
\text { наличие в ВНД банка (внутренних нормативных документах) разграничения функций } \\
\text { экспертизы проекта, принятия решения, мониторинга, контроля уровня риска, оценки } \\
\text { стоимости залога, работы с проблемной задолженностью }\end{array}$ \\
\hline 14 & $\begin{array}{l}\text { Организация юридическо- } \\
\text { го сопровождения }\end{array}$ & Правовая экспертиза документов службой юрисконсультов \\
\hline 15 & $\begin{array}{l}\text { Обеспечение } \\
\text { экономической } \\
\text { безопасности }\end{array}$ & Анализ заемщика ОБиЗИ (отделом безопасности и защиты информации) \\
\hline 16 & $\begin{array}{l}\text { Организация оценки } \\
\text { рисков }\end{array}$ & $\begin{array}{l}\text { Проработка стресс-сценария: } \\
\text { индексация ставки долгосрочной и краткосрочной аренды: первый год индексируется на темп } \\
\text { прироста инфляции, затем в течение } 6 \text { кварталов фиксированная, затем снова индексируется } \\
\text { на темп прироста инфляции } \\
\text { заполняемость БЦ - 85\% на протяжении всего периода прогнозирования, но снижается } \\
\text { до 50\% на протяжении 3-х кварталов подряд через } 1 \text { год после выдачи кредита (1 й квартал } \\
60 \%, 2 \text { й квартал 50\%, 3й квартал 60\%, затем восстановление до 85\%) }\end{array}$ \\
\hline
\end{tabular}

\section{Составлено автором}

ков (АРБ), где был создан Координационный комитет по стандартам качества банковской деятельности. К настоящему времени АРБ одобрено более 15 стандартов, основная часть которых - стандарты качества банковских бизнес-процессов, методологические документы.

Представляется, что назрела необходимость создания Стандарта процесса кредитования заемщиков под залог объектов коммерческой недвижимости как инструмента управления вышеуказанными кредитными и иными рисками.

Цель Стандарта - содействие развитию банковского кредитования под залог коммерческой недвижимости путем решения следующих задач:

- выработка единых требований и подходов к организации процесса кредитования под залог объектов коммерческой недвижимости;

- снижение кредитных и иных рисков;

- вовлечение в сферу кредитования под залог коммерческой недвижимости, банков, представителей бизнес-сообщества и др.

Целесообразность стандартизации залогового кредитования отмечается и в экономической литературе [4] [5].

Императивами Стандарта организации процесса кредитования под залог коммерческой недвижимости, в частности, являются: информация о заемщике; требования к компании, объекту коммерческой недвижимо- сти и к составу договорной и иной документации; рекомендации при расчете финансовой модели; условия погашения кредита и др.

Заинтересованными сторонами в использовании Стандарта, с точки зрения ожидаемого результата, являются:

- кредитные организации: повышение их конкурентоспособности, эффективности управления рисками, качества системы внутреннего контроля, снижение издержек, рост рентабельности кредитных операций;

- заемщики: стандартизированные требования к проектам, оценке кредитоспособности, мониторингу хода проекта, а также регламентация процесса выдачи, сопровождения и погашения ссуд.

Цели и задачи Стандарта, требования к заемщикам, предмету залога, структура финансовой модели отражаются в Матрице требований по составляющим процесса данного вида кредитования (см. табл. 1).

\section{Выво $\triangle \mathrm{b}$}

Одним из инструментов совершенствования бизнес-процесса кредитования компаний под залог коммерческой недвижимости, в целях снижения рисков сделок, является его стандартизация. Предлагаемый Стандарт находится на стыке двух направлений: продуктового и технологического. В нем содержатся требова- 
ния, во-первых, к банковскому продукту с учётом его качественных и количественных характеристик, во-вторых, к качеству оформления процесса и его составных частей. Центральный элемент Стандарта - построение финансовой модели в виде максимально детализированного плана снижения рисков при кредитовании. Внедрение Стандарта в банковскую практику будет способствовать непрерывному совершенствованию бизнес-процессов в целях снижения рисков банковского кредитования клиентов под залог коммерческой недвижимости.

\section{ЛИТЕРАТУРА}

1. Варфоломеева В.А., Иванова Н. А., Архипова И. И. Особенности предоставления коммерческой ипотеки юридическим лицам банками в Российской Федерации // Транспортное дело в России. 2017. N2. С. 31-33.

2. Перхайло В. В. Коммерческая ипотека в Российской Федерации: риск для банков, возможность для предпринимателей // Инновационная наука. 2016. № 1-3. C. 137-139.

3. Мартыненко Н. Н. Коммерческая ипотека для малого и среднего бизнеса: проблемы и перспективы внедрения // Современная наука: актуальные проблемы теории и практики. Серия «Экономика и право».—2014. -№ 11. -С. 66-70.

4. Семенова Н. Н. Залоговый механизм как эффективный способ обеспечения возвратности кредита // В сборнике: Современные проблемы и перспективы развития банковского сектора России. Материалы II всероссийской научно-практической конференции с международным участием (заочной). 2017. C. 389-397.

5. Никерясов А. В. Проблемы развития ипотеки под коммерческую недвижимость в России в современных условиях // Экономические науки. 2012. N87. C. 288-291.

() Ушанов Александр Евгеньевич (Ushanov_0656@mail.ru ).

Журнал «Современная наука: актуальные проблемы теории и практики»



